\title{
Nursing Informatics Education in the South: a Brazilian Experience
}

\author{
H. F. Marin \\ Universidade Federal de São Paulo, SP. Brazil
}

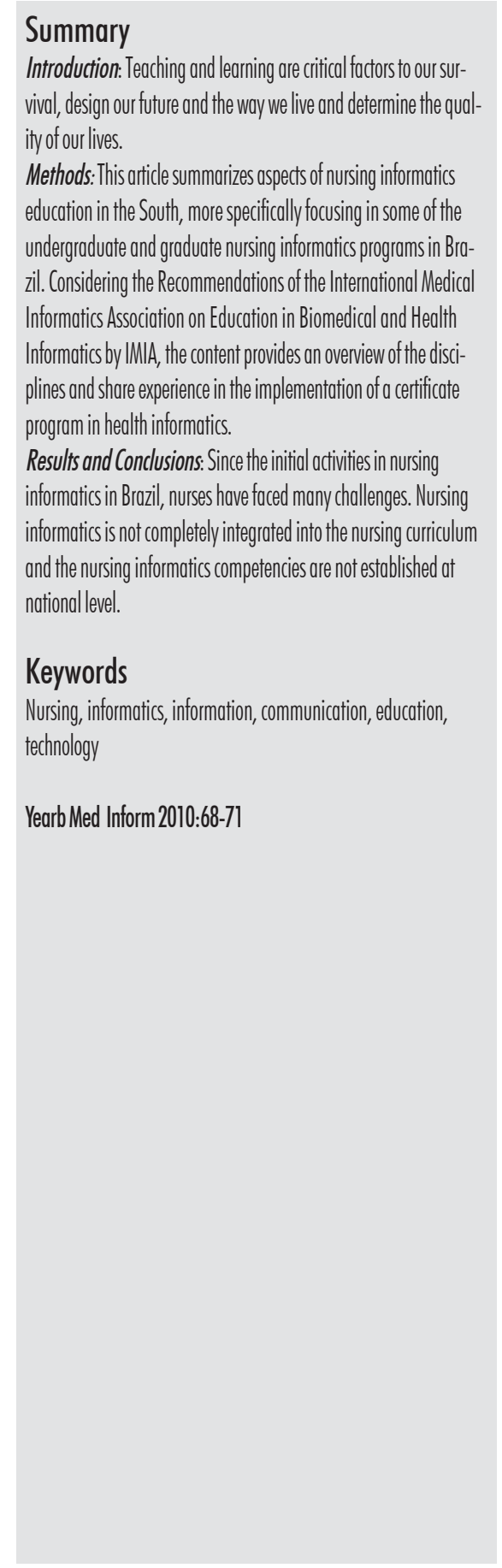

It is a miracle that curiosity survives formal education.

The important thing is not to stop questioning.

Albert Einstein (1879-1955)

\section{Introduction}

Education is long life value achieved by a continuous process. Teaching and learning are critical factors to our survival, design our future and the way we live and determine the quality of our lives.

Historically, educational strategies changed. However, the essence and fundamentals of educational principles remains in our society and communities as a process to reach development and to transmit values, culture aspects and civilization. Gilbert K Chesterton (18741936), an English writer quoted "education is simply the soul of a society as it passes from one generation to another."

Educational strategies are consistent with the development of communities and societies. In the healthcare area educational strategies to support today's human activities has changed significantly since traditional methods of teaching are no longer adequate to the requirements of modern life.

The field of health informatics has continually experienced extraordinary global growth. As consequence, increasing awareness of the need for trained personnel has led to the development of several training programs in different countries.

In 2000, the International Medical Informatics Association (IMIA) published the first version of the Recommendations on Education in Health and Medical Informatics [1]. Recently, a revision was prepared and published under the title of Recommendations of the International Medical Informatics Association on Education in Biomedical and Health Informatics [2]. As the title changed, the content presents new format and describes the educational needs for health care professionals in three-dimensional framework: (a) professionals in health care such as physicians and nurses; (b) type of specialization in biomedical and health informatics (users and specialists) and, (c) stage of career progression (bachelor, master, doctorate). The major motion to the revision was the tremendous progress and evolution of the field.

Consistent with the tendencies driven by IMIA, the International Medical Informatics Association, Nursing Informatics Special Interest Group (IMIA NI SIG) updated the definition of nursing informatics. In the Helsinki, Finland Congress - NI 2009, the definition approved is "Nursing informatics science and practice integrates nursing, its information and knowledge and their management with information and communication technologies to promote the health of people, families and communities worldwide."(http://www.imiani.org).

By the definition it can be observed how practice of nursing informatics is broad, ranging from clinical care settings to management of health services, health problems, research, training and education, as a major factor to assure the continuity of the field though future generations.

Nursing informatics education may also be considered from three requirements perspectives: (a) academics need to support teaching, training and research, (b) practice needs to support daily ac- 
tivities of caring for people and, (c) education to prepare nurse informatician [3].

In Brazil, education in nursing informatics was the preliminary activity in the field. The development of nursing informatics coincides with the establishment of nursing education programs with nursing informatics in the curriculum and the research. The pioneers of nursing informatics in the country were faculty and the first product of nursing informatics research was a teaching tool to document nursing data in home care.

The nursing education focus has been at both undergraduate and the graduate level. More recently, considering the advances in technology, distance education programs were added as a resource for certificate and continuous education programs.

This article summarizes aspects of nursing informatics education, more specifically focusing in some of the undergraduate and graduate nursing informatics programs available in Brazil.

\section{Undergraduate Program}

At the undergraduate level, most schools of nursing (629 in the country) integrated Nursing Informatics content into the curriculum. The majority recognize the importance of the teaching nursing informatics to prepare nurses for the future and even to work in the current scenario in healthcare area [4]. However, it must be said that several nursing directors still do not recognize nursing informatics as a discipline and as a result, they provide limited support and financial investments necessary to develop courses and to establish a laboratory for training students in the use of systems for nursing documentation, patient education or professional continuous education applications.

In summary, integration in nursing education remains a challenge and needs more efforts to assure that all nursing student in each of nursing school of the country be trained and educated on how search for information, how document patient and nursing data in order to re- trieve information for planning and research best care delivery.

The Nucleo de Informática em Enfermagem at the Universidade Federal de São Paulo (NIEn/ UNIFESP) was the first center to provide, since 1989, the nursing informatics discipline in its graduate and undergraduate nursing programs. In some sense, the Center was also responsible for the introduction of the discipline at several nursing schools in the country since many faculty were trained at this center. The student after graduation (master or doctoral degree) returns to their own institutes to implement education and research programs and to participate in the development of patient care systems.

In the early years the discipline was instrumental to provide resources in the use of computers, finding knowledge in the digital libraries, use internet and communication resources, including also concepts and definitions of hospital information systems, electronic patient record and nursing systems.

In the last eight years, the content on the undergraduate program emphasize the importance of the nursing documentation, nursing data sets, data acquired and data retrieval. The main objective of the discipline is to provide resources to recognize the needs and the structure for documenting nursing information, electronic health systems functionalities, nursing terminologies and how decision support systems can be used to assure and enhance patient safety. The content comprises identifying, collecting and recording data relevant to the nursing care. Students are requested to analyze and interpret patient and nursing data recorded into the patient record to plan and evaluate nursing care delivered under the concept of integration, interoperability, standardized terminologies for nursing applied on the Nursing Process. Concepts of privacy, confidentiality and security are also covered.

At most of nursing schools, the nursing informatics discipline at undergraduate programs comprises 36 hours of classes, where students are requested to attend at least $75 \%$.

\section{Certificate, Master and Doctoral Programs}

A significant effort to prepare professionals in health informatics is in place, provided by National and International Institutes. An example of international investments was a 4-year grant from the Fogarty International Center of the National Institutes of Health (U.S.), promoted the establishment of a bilateral consortium of health informatics faculty. A program was designed to enhance training in Brazil by augmenting the teaching resources of local faculty [5,6].

The program started in October 1999 and sponsored 10 onsite courses in Brazil, which were subsequently made available on the Internet and CD-ROM, together with regular medical informatics courses taught yearly at Harvard Medical School and Massachusetts Institute of Technology. The program started, in years 1 and 2 with activities targeted at faculty from leading universities in southern Brazil, which are better equipped with staff and material resources than universities in other parts of the country. There were short courses in Brazil, which were taught by a mix of Brazilian and U.S. faculty, as well as support for faculty enrichment via participation in international scientific events. In years 3 and 4, the training program was responsible for the organization of several scientific meetings in Brazil and continued to promote student and faculty participation in national and international conferences, short-term courses, and workshops.

During the development and implementation of this training program, different regions of Brazil were reached, delivering courses that were previously given in São Paulo or Rio de Janeiro. By the end of 2003, it was found that around 1,724 professionals were involved as either a faculty member or a student in the program.

The grant was renewed for the period from 2004 to 2009. In this second turn, the certificate program was the major activity of the project. We trained above 64 
professionals in a certificate program with one-year duration with 450 hours of classroom. This format showed that nurses were not the majority of the students ; we had physicians and computer science professionals or engineers as well.

The course comprised several disciplines such as Introduction of Health Informatics, Language Programs, Data Bank and Database design and implementation, Research Methodology, System Functionalities, Standards, Telemedicine, Management and Risk Analyzes, Computer as a resource for training and education and Decision Support Systems.

The limitation of this model of teaching was the in-place classroom education component without the distance education format. Several students were from different parts of the country and to remain one year in São Paulo, away from their universities and institutes was very time and resource consuming.

In 2008 was created by the Ministry of Education the Open University of Brazil, a common program of distance learning provided by UNIFESP that offers a specialized degree program on Health Care Informatics for 500 professionals at ten different centers spread throughout Brazil. In this year we decided to combine the Fogarty International Center of the National Institutes of Health (U.S.) grant with this distance education certificate program. The program was dedicated to health informatics, considering nursing infor-matics as part of a multidisciplinary course.

In 2009, the grant was renewed and more five years of training will be conducted. However, in the new funded grant we are involving the University of Maputo, Mozambique, Africa. We will deliver the distance program education in health informatics and select two students to obtain their graduation degree at the Federal University of São Paulo, Health Informatics Department.

It must be emphasized that the certificate program was initially provided by the Center of Nursing Informatics (NIEn/UNIFESP) and integrate with the Nursing Graduate Program of the Nursing School. However, in 2008, the directors of Nursing Research decided to change the researches area at the Nursing School. As a result, it was decided to combine nursing informatics with health Informatics graduate program offered by the Health Informatics Department. In this sense, nursing informatics students are no longer conducting studies at the Nursing School but at the Department of Health Informatics. This model is being implemented in several universities where nursing informatics is integrated in health informatics and nurses have the opportunity to discuss with colleagues of this multidisciplinary field.

Nevertheless, many dedicated courses are still in place. These programs focused on training nurses as users, developers, educators and researchers in nursing informatics. Courses in these programs aim to train professionals in order to improve the quality and safety of patient care along with improved outcomes through the development, implementation and evaluation of information and telecommunication tools. Examples of Universities and Nursing Schools offer graduate programs in Nursing Informatics include: the Nursing School of the State University of Sao Paulo (EEUSP); the Nursing School of Ribeirão Preto (EERP-USP); the Nursing School at Federal University of Santa Catarina (UFSC); and the Nursing School of the Federal University of Rio Grande do Sul (UFRGS) .

In general, the content for master and doctoral programs comprises the use of system applications to manage nursing and health data, information and knowledge; develop, implement and evaluate systems that support nursing practice; concepts of interoperability and integration; recognize needs for the practice of nursing including education, administration, research and practice; use and develop tools to support critical thinking in the nursing process record; system development life cycle and ability to implement and evaluate nursing care systems.

Currently, the Recommendations of the International Medical Informatics
Association on Education in Biomedical and Health Informatics [2] published by IMIA is being translated to the Brazilian Portuguese to be distributed to the faculty for adoption. However, several health informatics centers are already using those recommendations as a guide to establish the curriculum content for master and doctoral programs.

In March 2010, the Ministry of Health designated funds to support a distance program certificate for health care professionals in health Informatics. An agreement was signed involving four universities in the country that will organize and provide the courses dedicated to the training and education of 7000 professionals. The IMIA Recommendations of the International Medical Informatics Association on Education in Biomedical and Health Informatics was used to underpinned the program that will be available by September 2010.

\section{Continuous Education}

Since 2006, an important ICT project named RUTE network is being deployed in the country. The infrastructure was developed by the University Network of Telemedicine and Telehealth Care of the Science and Technology Ministry (MCT), which is coordinated by the National Network of Teaching and Research (RNP, 2009) and the National Program of Telehealth Care for primary health care. The RUTE project integrates teaching hospitals and the basic health care networks (PNT, 2009; Brasil, 2009). Currently, the RUTE network integrates approximately 57 health care institutes throughout the country and hundreds of basic health care units in their respective States, covering all Brazilian states. In addition, RUTE handles the multi-professional integration in the health care of the community, and this infrastructure has improved access to health care and health information for the populations that live in regions that are remote and difficult to reach $[7,8]$. 
The RUTE project also opened an on-going channel for the development of research studies and interchange of specialized health knowledge. This has resulted in the growth of scientific collaboration, increased enrollment in health care training courses and improved access to continuing education with the introduction of the e-learning on a national level [8].

Since its creation, it has been used by nurses across states to promote meetings and scientific discussions. The telecommunication resources made available can also be used as a tool used by nurses to support different activities in patient care delivery such as monitoring medications, fluids and feedings, elaborating physiological examination, clarifying instruction and helping patients to understand medical procedures, reducing doubts to promote better treatment adherence.

Up to now, the infra-structure built by RUTE is being used just for meetings and scientific discussion such case study. The development of a specific curricula for training in nursing domains is still being considered but not organized yet.

It is acknowledged that distance learning can be used to train large numbers of nurses in different geographic locations and work settings. To take advantage of the available resources in information technology, nurses should have a minimum of computer-based education established in their educational curriculum. Nurses with little or no previous experience in data standards and computer technology should receive basic training in the use of computer-supported nursing information systems or computer applications in nursing practice.

To stimulate the participation of nurses in the country, in February 2009, the first social web network was created on Nursing Informatics and Telenursing with the purpose of being an on-going source for nurses and other professionals for sharing information and innovations of knowledge as well as gather specialists for the development of nursing profession [9].

\section{Discussion}

Nurses must continue to ensure that information technology remains an integral part of professional practice and that computers are just an instrument with which they can acquire the information required. The information we share, we record and we analyze is the main aspect of nursing informatics and it will support the evaluation of our contribution to the healthcare services. It also allows us to develop new models that could better utilize resources to improve quality of care and professional performance [10].

Over the last years, since the pioneering initiatives in nursing informatics began, several important accomplishments were achieved to drive the profession and developments in support education, research and practice. It is clear however, that technology is the means but not the final product of accomplishing nursing care.

Since the initial activities in nursing informatics in Brazil, nurses have faced many challenges. Nursing informatics is not completely integrated into the nursing curriculum and the nursing informatics competencies are not established at national level.

Leading members of the Brazilian Health Informatics Nursing Informatics Group, consider the IMIA NI SIG Strategic Plan [11] as a guide to drive national activities and are working to establish a national plan that includes the: (1) definition of nursing informatics competencies and the integration of nursing informatics into the nursing curriculum; (2) development of links with the nursing associations; (3) seeking of participations from nurses across country; (4) promotion of conferences to serve as a forum where experiences in nursing informatics can be shared; (5) expansion of users of interest to develop interdisciplinary and multicentric researches; (6) promotion of new technologies to empower patients and their caregivers for collaborative knowledge development; and (7) encouragement of innovative methodologies in education, research and care delivery congregating human-computer interaction, organizational context and the needs of the society [12].

\section{References}

1. Recommendation of the International Medical Informatics Association (IMIA) on education in health and medical informatics. Methods Inf Med 2000;39:267-77.

2. Mantas J, Ammenwerth E, Demiris G, Hasman A, Haux R, Hersh W, Hovenga E, Lun KC, Marin H, Martin-Sanchez F, Wright G. Recommendations of the International Medical Informatics Association (IMIA) on Education in Biomedical and Health Informatics. Methods Inf Med 2010;49:1-16. doi 10.3414/ME51119.

3. Marin HF, Rodrigues RJ, Delaney C. Nielsen GH, Yan J. Building Standard-Based Nursing Information systems. PAHO, WHO; 2001. p. 27-45.

4. Sasso GT, Silveira DT, Peres HHC, Marin HF. The Americas: Case Study 14H: Brazil. In: Weaver CA, Delaney CW, Weber P, Carr R. Nursing and Informatics for the $21^{\text {st }}$ Century, $2^{\text {nd }}$ edition, HIMSS. In press 2010.

5. Marin HF, Massad E, Marques EP, Ohno-Machado L . International Training in Health Informatics: a Brazilian experience. In: MEDINFO'2004. 2004; San Francisco. MEDINFO'2004; 2004. p. 898-902.

6. Marin HF, Massad E, Marques EP, Azevedo R, Ohno-Machado L. Health informatics education in Brazil. In: 19th International Congress of the European Federation for Medical Informatics 2005; Genebra. Abstract, 2005. v. 116. p. 1126-31.

7. Rede Nacional de Ensino e Pesquisa. RNP. Available at: htttp://www.rnp.br/index.php. Accessed February 12, 2010.

8. Rede Universitária de Telemedicina e Telesaúde. RUTE. Available at: http://rute.mp.br. Accessed February 12, 2010.

9. INFOTELEN. Brazil's Nursing and Telenursing Network. Available at: http://www.infotelen. ning.com. Accessed June, 2009

10. Marin HF, Marques EP. Nursing Informatics: learning from the past to build a new future. Rev Bras.Enferm.2005;58(2):143-6.

11. IMIA-NI Strategic Plan-Towards IMIA-NI 2015. Ratified August 2007 http://fayre.org/imiani/ index.php?option=com_docman\&task= cat_view\&gid $=16 \&$ Itemid $=30$

12. Marin HF, Silveira DT, Dal Sasso GT, Perez HHC. Nursing Informatics in Brazil: evolution, current aspects and tendencies. In: Ball M, Douglas JV, Newbold SK, editors. Nursing Informatics: where caring and technology meet, 4.Ed. New York: Springer. In Press 2010.

\section{Correspondence to:}

Heimar F. Marin, RN, PhD. FACMI

Professor, Universidade Federal de São Paulo

Chair of IMIA NI SIG

Rua Dep. Bady Bassit 440

05517-050 São Paulo - SP - Brazil

E-mail: hfmarin@unifesp.br por heimarfm@gmail.com 